\title{
Interpreting Process Analyzed Based on the Multidirectional Reformulation Activities of New Learners
}

\author{
Hiroko Yamada \\ Kansaigaidai College, Osaka, Japan
}

\begin{abstract}
Aiming at a comprehensive account of interpreting processing, this paper first examines the efficacy of reformulation activities employed in interpreting classes at a university and then analyzes the reformulating products so as to explore the comprehension and the reformulation phases in line with three distinguished hypotheses. They are the meaning-based comprehension (deverbalization) and the form-based comprehension, both of which have the precedence over reformulation phase, and the TL parallel processing occurring during the SL comprehension, in which language-pair specific process is discussed by investigating multi-directional language combinations: from $L 1$ to $L 1, L 1$ to $L 2, L 2$ to $L 2$, and $L 2$ to $L 1$ reformulations. The main findings of this study suggest that the process of reformulating varies, depending on specific language pairs, which may shed light on the salient link between language combinations and the interpreting process.
\end{abstract}

Index Terms —reformulation, interpreting process, meaning-based, form-based, parallel processing

\section{INTRODUCTION}

To date, a substantial body of language-processing research has focused on comprehension, whereas production processes have received less attention in both cognitive science in general and, more specifically, the cognitive processing paradigm of interpreting studies (Pöchhacker, 2016). In fact, few studies may be found that analyze the methodology of the interpretation process. For example, analyzing the think-aloud method while the subject is performing a task is impossible because the interpreter cannot both interpret and verbalize about the process at the same time (Tiselius \& Jenset, 2011). Another form of verbal report is immediate retrospection, in which the subjects recall and verbalize their memories of the process shortly after the interpreting task is finished by using the source text as cues; this method has been popular in expertise research (Alvstad, Hild, \& Tiselius, 2011).

When discussing the interpretation process, interpreting scholars commonly invoke the Interpretive Theory of Translation (ITT; Seleskovitch, 1978), which states that the linguistic units in the original message are first converted into "deverbalized structures," or units of sense, and subsequently reformulated in the target language. This is the most fundamental and persistent claim regarding the interpreting process that has prevailed to date. However, some scholars have presented a contrasting theory. Dam (2002) claimed that meaning representation should be qualified as verbalized because of the high degree of formal-lexical similarity observed between the source and the target texts. He argued that interpreting is based on form or "transcoding" (Gran, 1989) rather than on meaning; that is, interpreting generally proceeds on the basis of verbal representation rather than non-verbal. However, other scholars hold dissenting views regarding the sequential process of interpreting. The theoretical model of the interpreting process in ITT consists of three stages: 1) comprehension, 2) deverbalization, and 3) reformulation, which claims that language reformulation starts only after source language comprehension has been completed. However, some scholars argue that target language (TL) processing occurs during source language (SL) comprehension: in other words, that the target language and source language comprehension occur in parallel (Dong \& Lin, 2013; Jin, 2010; Macizo \& Bajo, 2004, 2006). In this context, the present study addresses conceptual representation in the comprehension process by examining whether SL comprehension is verbalized or deverbalized, which has precedence over the reformulation phase; otherwise, comprehension is exercised parallel to reformulation, the two being inseparable.

Language reformulation in interpreting refers to using the source language (SL) or the target language (TL) to rephrase the message spoken in the SL. First, the present study examines oral language reformulation activities administered to students in an introductory interpreting course at a university in Japan. Research participants took an English/Japanese interpreting class, held for 3 hours a week for a total of 15 lessons during a semester. During each lesson, 1 hour of oral language reformulation activities were provided to the students in four language directions - that is, from SL to SL, SL to TL, TL to TL, and TL to SL. More specifically, reformulation practices were administered from English to English, from English to Japanese, from Japanese to Japanese and from Japanese to English. Then, the students' reformulating abilities were tested in two developmental stages: a mid-term and a final examination were implemented at the middle and end of the semester, which the present study uses to examine the efficacy of the students' reformulation activities by comparing their reformulated products. Structural, semantic, and pragmatic comparative analyses were used to investigate students' development in reformulation abilities over the semester. Then, 
the multi-directional reformulating products were examined to analyze correlations in specific language pairs based on the compositional meaning arising from lexemes and syntax. Parallel to this analysis, the strategies that the students employed to solve specific processing problems are also discussed.

Next, the present study addresses conceptual representation in the initial comprehension process by examining whether the SL comprehension is verbalized or deverbalized, which has precedence over the reformulation phase; otherwise, comprehension is exercised in parallel with reformulation, the two being inseparable, which serves as the main signification of the present study. It is likely that various types of compensation for cognitive overload may be exercised during the process; thus, reaction time is also measured to explore the cognitive process in comprehension and reformulation. However, this is a product-oriented study, so it focuses on the reformulated products. The main purpose of this study was to shed light upon the process of consecutive interpreting based on the above-mentioned three theoretical constructs that have commonly prevailed to date.

\section{BACKGROUND}

The most prominent theory about the interpretation process, the Interpretive Theory of Translation (ITT), was propounded by Danica Seleskovitch in the 1970s, and it has been predominantly supported by the scholars of the so-called Paris School. It proposes that the essential mechanism of the interpreting process is deverbalization or interpreters' non-verbal understanding and expression of "sense," not "transcoding," which is limited to items with fixed correspondences, such as correct names, numbers, and specialized terms. Seleskovitch (1978a) states that "sense" is 1) "conscious," 2) "made up of the linguistic meaning aroused by speech sounds and cognitive complements of the listeners," and 3) "nonverbal," which means that is not contained in any language or text but arises from cues given by the language of oral discourse.

However, not all scholars have supported this theoretical model. Setton (1999), in his research on the cognitive-pragmatic analysis of the interpreting process, although fundamentally sympathetic to ITT, disqualifies the key notion of "sense" as essentialistic and underspecified (Pöchhacker, 2016). Currently, the idea prevails that the cognitive process uses a language of intermediate representation, but Setton (2002) suggested that it comprises a vocabulary to (meta)represent concepts, intentions, attitudes, and a syntax of deductive procedures for inference, with an unspecified influence of affect and instinct on both. Gill (2009) noted that although the Paris philosophy was predominant mainly in the 1970s and 1980s, it has little impact on present-day interpreting studies. He established effort models to explain the interpreters' processing capacity as a conceptual tool, considering performance limitations as a result of cognitive constraints. Cokely (1992a) explicitly considered the modality of input and output process of consecutive interpreting by illustrating seven major processing stages from message reception to production, as follows: message reception, preliminary processing, short-term message retention, semantic intent realization, semantic equivalence determination, syntactic message formulation, and massage production.

Dam (2002) explored the process of consecutive interpreting by comparing the products of the source text and the target text, in which he presented the contrasting theory to ITT's "meaning-based interpreting." He propounded the theoretical constructs of "form-based (or word-based)" interpreting or "transcoding" (Dam, 2001; Gran, 1989), his findings suggesting that meaning representation should be qualified as verbalized because of the high degree of formal-lexical similarity observed throughout in the corpus between the source and the target texts. Dam argued that this phenomenon would be unlikely to have occurred if the interpreters had performed a complete deverbalizaion of the source text before note-taking and, subsequently, target text production (Dam, 2002).

Another theoretical model in the reformulation process is parallel processing of the target language during source language comprehension (Dong \& Lin, 2013; Jin, 2010; Macizo \& Bajo, 2004, 2006). Dong and Lin (2013) conducted an experiment to investigate reading an L1 or L2 sentence for repetition or interpreting tasks in which the sentence includes cross-linguistic features - for example, cognateness or the processing load of sentences, such as the working memory load. Then, they found that parallel processing of the TL occurred during SL comprehension; however, the TL was not always being processed during SL comprehension; rather, only in the case of L2-L1 interpretation does parallel processing occur (Dong \& Lin, 2013).

In the present study, the reformulating products from the students are analyzed according to multidirectional language pairs so as to verify the above-mentioned three contradicting theoretical constructs: conceptual representation based on meaning (deverbalized form), form (verbalized form), or parallel processing, which may serve to clarify the interpreting process. In this context, the author presents the following research questions.

\section{RESEARCH QUESTIONS}

1) Would intensive language reformulation activities, if administered to university students over a limited time span, develop their abilities in reformulation as well as in consecutive interpreting?

) Would source language comprehension and reformulation in consecutive interpreting be realized on meaning-based (deverbalization) or on form-based (word-by-word) processing, or in parallel processing with the target language?

\section{METHOD}




\section{Research Participants}

The research was conducted during Spring Semester 2017 at the Japanese university where the author taught. Research participants consisted of 27 students in their third and fourth year as English majors, who were registered in English-to-Japanese interpreting introductory courses and who had never undergone interpreter training in the past.

Procedures

For the present research, intensive reformulation treatments were administered for 1 hour in a 3-hour weekly lesson, totaling 15 lessons in the whole semester. All lessons were carried out in the CALL room where the textbooks used for the reformulation activities specialized in interpreting studies. Reformulation activities entailed the following tasks, which were applied in the following order.

Training in reformulation from SL (English) to SL (English)

1) Listening

Wearing headsets, students listened to the English text throughout once with the textbook closed to learn the outline of the source text.

2) Oral representation as rehearsal and monitoring

The students were asked to listen to one to four English sentences at a time with the textbook closed while taking notes and then to reformulate verbally or recreate the message in English aloud as accurately as possible all together, using the microphones attached to the headsets. Each student's performance was monitored by the author, and instructions were given to the selected student if necessary, an interaction that could be heard only by the student and the author.

3) Oral representation on the real stage

A student was then selected and asked to perform a complete oral reformulation of the message that had been previously listened to and tried in 2). This effort was heard not only by the author but also by the other students in the classroom. If a specific student could not reformulate the sentences, another student was named. The author provided suggestions, comments, and corrections when each student's performance was finished.

4) Recording the individual student's performance

In order to identify the specific causes of reformulation problems, the students were asked to record their reformulation performances into their own computers and subsequently listen to them carefully with the text open to discover strategies for solving specific processing problems. Recordings of their output performances were repeated several times to raise the quality of their performances.

Training in reformulation from SL (English) to TL (Japanese), from SL (Japanese) to SL (Japanese), and from SL (Japanese) to TL (English) followed the same procedures as the case from SL (English) to SL (English).

\section{Data Collection}

Data were collected on two occasions: at the midterm examination, held at the end of the eighth lesson, and at the final examination, implemented after the 15th lesson was completed. The subjects consisted of 27 students. The test procedures proceeded as follows, in which the duration of the time used for 1) to 4) was 60 minutes in total for the midterm and final examinations, respectively.

The procedures of the mid-term examination or final examination

1) The students were asked to listen to one paragraph consisting of three to four sentences one at a time in the SL text narrated in English. The source text was unknown material that they had never tried to interpret before.

2) They proceeded to perform immediate verbal reformulation of the paragraph they had just heard in English, and subsequently, reformulation of the same paragraph in Japanese. The time limit depended on the length of a paragraph. The reaction time entailed by each reformulation was displayed on each student's computer. The total number of test items was three.

3) They were asked to perform consecutive interpreting for some source materials that were not relevant to the present research, which took around 30 minutes. The irrelevant test items were inserted here in order to reduce the practice effect that might be induced by the first reformulation test 1) and applied to the following reformulation test 4).

4) The students were asked to listen to the same paragraphs they had tried in 1) and 2), but this time narrated in Japanese. The Japanese version exactly matched the English one. Students performed the reformulation for it from Japanese to Japanese first, and then from Japanese to English. All performances and the reaction time were recorded in each student's computer, which were copied onto a USB flash drive and then assessed by the author.

\section{Materials}

The test items for both examinations were taken from a textbook (Mukai, Maruyama \& Matsuoka, 2004) that was designed for beginners' training in interpreting, and offered bidirectional interpreting practice using the same source texts both in the English and Japanese versions, in the fields of cross-cultural communication, culture, environment, and politics. Excerpts from the test items are provided below. The difficulty levels of the source texts for both examinations in terms of intelligibility, syntactic complexity, vocabulary, and familiarity with the source text information are almost equivalent, and both speeches were recorded by the same speaker. The speech comprised 100 words for the midterm examination, and 112 words for the final examination, organized into three paragraphs for both examinations, and heard by the students for the purpose of reformulation. 
Final examination

English version

Good afternoon, everyone. Thank you for having this reception party for us. My name is Robert Millar. Please call me Bob...... So during my stay here, I'd like to learn as much as possible about your lovely country and people. So, please help me in any way you can. Thank you again for your kindness and hospitality.

Japanese version

(Mukai, Maruyama, \& Matsuoka, 2004)

こんにちは皆さん。私たちのために歓迎会を開いていただき、ありがとう

ございます。私の名前はロバートミラーです。どうぞバブと呼んでください。

…ですので、ここに滞在中に、皆様の素晴らしい国と人々について、

できるだけ勉強したいと思っています。ですからどうぞ何でもご助言下さい。

\section{Measurement}

皆様のご親切とご好意に対してもう一度お礼申し上げます。

The reformulating performances in four directions, namely from English to English, from English to Japanese, from Japanese to Japanese, and from Japanese to English were analyzed with reference to Viaggio's (1992) criteria.

1) Comprehension (Has the student understood everything and right?)

2) Re-expression (Did the student make any syntactic or lexical mistakes?)

3) Style (Could it have been expressed better?)

More specifically, according to each phrase or semantic chunk, the recorded performances were assessed in every detail, based on the scoring rubric that the author had created (Yamada, 2015), to which specific points were allocated based on the difficulty of translating each semantic chunk or phrase. In order to ascertain the difficulty level of a specific word, a "word frequency list" from an academic area was used (http://www.wordandphrase.info/frequencyList.asp). Using this analytic protocol, the data were analyzed using an F test and a t test.

Results

Comparative analysis was conducted on the marks obtained in reformulation between the mid-term and the final examinations, which are shown in Tables 5-8. Full marks equal 30 points.

TABLE 1

COMPARISON OF MARKS OBTAINED IN REFORMULATION FROM ENGLISH TO ENGLISH ON THE MIDTERM AND THE FINAL EXAMINATION

\begin{tabular}{lllll}
\hline & $\mathrm{N}$ & Mean & SD & $t$ \\
\hline Mid-term (E-E) & 27 & 21.89 & 5.80 & -1.47 \\
\hline Final (E-E) & 27 & 23.15 & 4.23 & -1.47 \\
\hline
\end{tabular}

TABLE 2.

COMPARISON OF MARKS OBTAINED IN REFORMULATION FROM ENGLISH TO JAPANESE ON THE MIDTERM AND THE FINAL EXAMINATION

\begin{tabular}{|c|c|c|c|c|}
\hline & $\mathrm{N}$ & Mean & SD & $t$ \\
\hline Mid-term (E-J) & 27 & 20.78 & 6.48 & -2.16 \\
\hline Final (E-J) & 27 & 22.70 & 4.56 & -2.16 \\
\hline
\end{tabular}

TABLE 3.

COMPARISON OF MARKS OBTAINED IN REFORMULATION FROM JAPANESE TO JAPANESE ON THE MIDTERM AND THE FINAL EXAMINATION

\begin{tabular}{lllll}
\hline & $\mathrm{N}$ & Mean & SD & $t$ \\
\hline Mid-term $(\mathrm{J}-\mathrm{J})$ & 27 & 28.93 & 2.59 & -1.27 \\
\hline Final $(\mathrm{J}-\mathrm{J})$ & 27 & 29.52 & 0.76 & -1.27 \\
\hline
\end{tabular}

Note: J-J: reformulation from Japanese to Japanese

TABLE 4.

COMPARISON OF MARKS OBTAINED IN REFORMULATION FROM JAPANESE TO ENGLISH ON THE MIDTERM AND FINAL EXAMINATIONS

\begin{tabular}{lllll}
\hline & $\mathrm{N}$ & Mean & SD & $t$ \\
\hline Mid-term $(\mathrm{J}-\mathrm{E})$ & 27 & 24.07 & 6.18 & -2.60 \\
\hline Final $(\mathrm{J}-\mathrm{E})$ & 27 & 26.52 & 2.91 & -2.60 \\
\hline \multicolumn{5}{c}{ Note: ${ }^{*} p<.05 \mathrm{~J}-\mathrm{E}:$ reformulation from Japanese to English }
\end{tabular}

As shown, when we compare the midterm examination to the final examination, the difference in the marks obtained in the reformulation from the SL to the SL-namely, from English to English and Japanese to Japanese-was not statistically significant between the midterm and the final examinations. However, with respect to the reformulations from the SL to the TL (from English to Japanese, and from Japanese to English), the difference was statistically significant in both directions: marks obtained in the final examination were significantly higher than those in the midterm examination. This finding demonstrates that the selected variables are significant predictors of marked development in students' reformulation abilities from the SL to the TL, which are equated with consecutive interpreting 
skills from English to Japanese and from Japanese to English. It suggests that the intensive reformulation activities applied during a semester may be effective in consecutive training periods for interpreting, while with regard to the reformulation from the SL to the SL (English to English, and Japanese to Japanese), distinctive improvement was not observed during the semester.

Turning to the standard deviation, the value for the midterm examination is much higher than that for the final examination in every language pair, which reveals that the accuracy of students' reformulation performance varies more significantly in the midterm examination than in the final. The measurement models assume that at the initial stages of reformulation activities, the students' performances varied more in quality, which was generally quite low. Nonetheless, as the lessons proceeded, some students who had not displayed good skills in reformulation may have developed their abilities in reformulation, which resulted in less deviation in quality among the students.

Further, to explore the efficacy of the treatment of the SL to SL reformulation and the SL to TL reformulation, the causal relation in products between two language pairs was investigated. The findings showed that with respect to reformulation from English to English, and from English to Japanese, the correlation was high for the midterm examination $\left(\mathrm{r}=.80^{* *}\right)$ and for the final examination $\left(\mathrm{r}=.88^{* *}\right)$. In contrast, the Japanese to Japanese reformulation and its Japanese to English counterpart yielded a low correlation for the midterm examination $(r=.36)$, and for the final examination $(r=.49)$. This suggests that on the one hand, the students who display superior performance with English to English reformulation are also superior in English to Japanese reformulation, which reveals that reformulation activities from English to English are effective in developing consecutive interpreting abilities from English to Japanese, whereas Japanese to Japanese reformulation activity may not directly contribute to development in Japanese to English consecutive interpreting.

Though these data suggest important observations concerning the efficacy of reformulation activity in specific language pairs during interpreting training, reaction time needed to be investigated next so as to obtain further evidence of the effectiveness of the treatment. Reaction time, which was defined as the interval between stimulation and response (http://www.dictionary.com/browse/reaction-time), indicates cross-linguistic effects or load effects in the comprehension and reformulation phases. To examine the cross-linguistic features, the reaction times in English to Japanese and Japanese to English reformulations were measured, including the time from students' receiving the instruction to their starting the verbal production to completing their verbal output. The data was analyzed by using a $t$ test and an F test; the results are presented in Table 9.

TABLE 5.

COMPARISON OF REACTION TIME IN REFORMULATION FROM ENGLISH TO JAPANESE ON THE MIDTERM AND THE FINAL EXAMINATION

\begin{tabular}{lllll}
\hline & $\mathrm{N}$ & Mean $(\mathrm{Sec})$ & $\mathrm{SD}$ & $t$ \\
\hline Mid-term (E-J) & 27 & 92.26 & 19.01 & 3.96 \\
\hline Final (E-J) & 27 & 75.37 & 10.46 & 3.96 \\
\hline \multicolumn{5}{c}{ Note: *** $p<.001$}
\end{tabular}

TABLE 6.

COMPARISON OF REACTION TIME IN REFORMULATION FROM JAPANESE TO ENGLISH ON THE MIDTERM AND THE FINAL EXAMINATION

\begin{tabular}{lllll}
\hline & $\mathrm{N}$ & Mean $(\mathrm{Sec})$ & $\mathrm{SD}$ & $t$ \\
\hline Mid-term (J-E) & 27 & 112.33 & 24.98 & 5.37 \\
\hline Final (J-E) & 27 & 86.70 & 13.91 & 5.37 \\
\hline \multicolumn{5}{c}{ Note: *** $p<.001$}
\end{tabular}

The results showed that the students developed markedly also in reaction time with English to Japanese reformulation $(\mathrm{p}<.001)$ as well as its Japanese to English counterpart $(\mathrm{p}<.001)$ between the mid-term and the final examination. In summary, it is most likely that the students developed their abilities of L2 to L1 and L1 to L2 reformulations in terms of not only the obtained marks but also the reaction time.

Next, ANOVAs were performed to investigate the variance of the four variables; these results are presented in Tables 11 and 12.

TABLE 7.

ANALYSIS OF VARIANCE OF REFORMULATION IN THE FOUR LANGUAGE PAIRS ON THE MIDTERM EXAMINATION.

\begin{tabular}{llll}
\hline Reformulation & Mean & SD & F \\
\hline English to English & 21.89 & 5.80 & $2.69 * * *$ \\
English to Japanese & 20.78 & 6.48 & \\
Japanese to Japanese & 28.93 & 2.59 & 6.18 \\
Japanese to English & 24.07 & Note: $\mathrm{N}=27 . * * *<0.001$
\end{tabular}

TABLE 8.

ANALYSIS OF VARIANCE OF REFORMULATION IN THE FOUR LANGUAGE PAIRS ON THE FINAL EXAMINATION

\begin{tabular}{lccc}
\hline Reformulation & Mean & SD & F \\
\hline English to English & 23.15 & 4.23 & $2.69 * * *$ \\
English to Japanese & 22.70 & 4.56 & 0.75 \\
Japanese to Japanese & 29.52 & 2.91 & \\
Japanese to English & 26.52 & Note: $\mathrm{N}=27 * * *<0.001$
\end{tabular}


The results for the four language combinations were significantly different between the midterm examination $(\mathrm{F}(3.10)=2.69, p<.001)$ and the final examination $(\mathrm{F}(3.10)=2.69, p<.001)$. Interestingly, in both midterm and final examinations, the same rankings were observed: the Japanese to Japanese combination had the highest score, followed by Japanese to English, then English to English, and finally English to Japanese.

Further, to explore the multi-directional reformulation processes, an $\mathrm{F}$ test and test were performed on every possible language pair to investigate how two languages in a bilingual speaker interact during a specific language process. These tests were carried out for both the mid-term and final examinations. The results are displayed in Tables 9 and 10.

TABLE 9.

DESCRIPTIVE STATISTICS OF MARKS OBTAINED IN REFORMULATION ON THE MIDTERM EXAMINATION (FULL MARKS ARE 30 POINTS).

\begin{tabular}{|c|c|c|c|c|}
\hline Reformulation & $\mathrm{N}$ & Mean & SD & $t$ \\
\hline English to English & 27 & 21.89 & 5.80 & 1.47 \\
\hline English to Japanese & 27 & 20.78 & 6.48 & 1.47 \\
\hline Reformulation & $\mathrm{N}$ & Mean & SD & $t$ \\
\hline English to English & 27 & 21.89 & 5.80 & -6.87 \\
\hline Japanese to Japanese & 27 & 28.93 & 2.59 & -6.87 \\
\hline \multicolumn{5}{|c|}{ Note: $* * * p<.001$ Full marks are 30 points. } \\
\hline Reformulation & $\mathrm{N}$ & Mean & SD & $t$ \\
\hline English to English & 27 & 21.89 & 5.80 & -2.72 \\
\hline Japanese to English & 27 & 24.07 & 6.18 & -2.72 \\
\hline \multicolumn{5}{|c|}{ Note: $* p<.05$} \\
\hline Reformulation & $\mathrm{N}$ & Mean & SD & $t$ \\
\hline English to Japanese & 27 & 20.78 & 6.48 & -6.19 \\
\hline Japanese to Japanese & 27 & 28.93 & 2.59 & -6.19 \\
\hline \multicolumn{5}{|c|}{ Note: $\quad * * * p<.001$} \\
\hline Reformulation & $\mathrm{N}$ & Mean & SD & $t$ \\
\hline English to Japanese & 27 & 20.78 & 6.48 & -2.80 \\
\hline Japanese to English & 27 & 24.07 & 6.18 & -2.80 \\
\hline
\end{tabular}

\begin{tabular}{lllll}
\hline Reformulation & N & Mean & SD & $t$ \\
\hline Japanese to Japanese & 27 & 28.93 & 2.59 & 4.36 \\
\hline Japanese to English & 27 & 24.07 & 6.18 & 4.36 \\
\hline \multicolumn{5}{c}{ Note: *** $p<.001$}
\end{tabular}

TABLE 10.

DESCRIPTIVE STATISTICS OF MARKS OBTAINED IN REFORMULATION ON THE FINAL EXAMINATION (FULL MARKS ARE 30 POINTS.)

\begin{tabular}{|c|c|c|c|c|}
\hline Reformulation & $\mathrm{N}$ & Mean & SD & $t$ \\
\hline English to English & 27 & 23.15 & 4.23 & 1.05 \\
\hline English to Japanese & 27 & 22.70 & 4.56 & 1.05 \\
\hline Reformulation & $\mathrm{N}$ & Mean & SD & $t$ \\
\hline English to English & 27 & 23.15 & 4.23 & -8.52 \\
\hline Japanese to Japanese & 27 & 29.52 & 0.75 & -8.52 \\
\hline \multicolumn{5}{|c|}{ Note: $* * * p<.001$} \\
\hline Reformulation & $\mathrm{N}$ & Mean & SD & $t$ \\
\hline English to English & 27 & 23.15 & 4.23 & -6.76 \\
\hline Japanese to English & 27 & 26.52 & 2.91 & -6.76 \\
\hline \multicolumn{5}{|c|}{ Note: $* * * p<.001$} \\
\hline Reformulation & $\mathrm{N}$ & Mean & SD & $t$ \\
\hline English to Japanese & 27 & 22.70 & 4.56 & 1.71 \\
\hline Japanese to Japanese & 27 & 29.52 & 0.75 & 1.71 \\
\hline \multicolumn{5}{|c|}{ Note. $* * * p<.001$} \\
\hline Reformulation & $\mathrm{N}$ & Mean & SD & $t$ \\
\hline English to Japanese & 27 & 22.70 & 4.56 & -6.08 \\
\hline Japanese to English & 27 & 26.52 & 2.91 & -6.08 \\
\hline \multicolumn{5}{|c|}{ Note. $* * * p<.001$} \\
\hline Reformulation & $\mathrm{N}$ & Mean & $\mathrm{SD}$ & $t$ \\
\hline Japanese to Japanese & 27 & 29.52 & 0.75 & 5.92 \\
\hline Japanese to English & 27 & 26.51 & 2.91 & 5.92 \\
\hline
\end{tabular}


Interestingly enough, for both the midterm and final examinations, in only one instance-that is, the paired reformulations from English to English and from English to Japanese-were the results not significantly different from each other. The five other pairs were statistically different. Turning to the standard deviation, in both the midterm and final examinations, the highest values show in the reformulation from English to Japanese, and the lowest values are in the reformulation from Japanese to Japanese. This finding indicates that the students' abilities vary most significantly in English to Japanese reformulation-i.e., English to Japanese consecutive interpreting-whereas Japanese to Japanese is much more standardized among the students.

Parallel to the marks obtained, the reaction time was also measured in four language pairs, as shown in Tables 11 and 12 .

TABLE 11.

DESCRIPTIVE STATISTICS OF REACTION TIME FOR REFORMULATION ON THE MIDTERM EXAMINATION

\begin{tabular}{|c|c|c|c|c|}
\hline Reaction Time & $\mathrm{N}$ & Mean $(\mathrm{sec})$ & SD & $t$ \\
\hline English to English & 27 & 95.37 & 17.20 & 0.55 \\
\hline English to Japanese & 27 & 92.26 & 19.01 & 0.55 \\
\hline Reaction Time & $\mathrm{N}$ & Mean $(\mathrm{sec})$ & SD & $t$ \\
\hline English to English & 27 & 95.37 & 17.20 & 7.11 \\
\hline Japanese to Japanese & 27 & 68.59 & 8.78 & 7.11 \\
\hline \multicolumn{5}{|c|}{ Note: $* * * \mathrm{p}<.001$} \\
\hline Reaction Time & $\mathrm{N}$ & Mean $(\mathrm{sec})$ & SD & $t$ \\
\hline English to Japanese & 27 & 92.26 & 19.01 & 7.11 \\
\hline Japanese to English & 27 & 112.33 & 24.93 & 7.11 \\
\hline \multicolumn{5}{|c|}{ Note: $* * * p<.001$} \\
\hline Reaction Time & $\mathrm{N}$ & Mean $(\mathrm{sec})$ & SD & $t$ \\
\hline Japanese to Japanese & 27 & 68.59 & 8.78 & -8.08 \\
\hline Japanese to English & 27 & 112.33 & 24.98 & -8.08 \\
\hline
\end{tabular}

TABLE 12.

DESCRIPTIVE STATISTICS OF REACTION TIME FOR REFORMULATION ON THE FINAL EXAMINATION

\begin{tabular}{|c|c|c|c|c|}
\hline Reaction Time & $\mathrm{N}$ & Mean $(\mathrm{sec})$ & SD & $t$ \\
\hline English to English & 27 & 74.33 & 10.53 & -0.38 \\
\hline English to Japanese & 27 & 75.37 & 10.46 & -0.38 \\
\hline Reaction Time & $\mathrm{N}$ & Mean $(\mathrm{sec})$ & SD & $t$ \\
\hline English to English & 27 & 74.33 & 10.53 & 0.91 \\
\hline Japanese to Japanese & 27 & 72.48 & 8.45 & 0.91 \\
\hline Reaction Time & $\mathrm{N}$ & Mean $(\mathrm{sec})$ & SD & $t$ \\
\hline English to Japanese & 27 & 75.37 & 10.46 & -4.86 \\
\hline Japanese to English & 27 & 86.70 & 13.91 & -4.86 \\
\hline \multicolumn{5}{|c|}{ Note: $* * * p<.001$} \\
\hline Reaction Time & $\mathrm{N}$ & Mean $(\mathrm{sec})$ & SD & $t$ \\
\hline Japanese to Japanese & 27 & 72.48 & 8.45 & -6.00 \\
\hline Japanese to English & 27 & 86.70 & 13.91 & -6.00 \\
\hline
\end{tabular}

Only one pair did not produce a statistical difference in reaction time in the midterm and final examination-the reformulation from English to English and from English to Japanese-thus matching the results for the tests with regard to marks obtained.

Processing Problems and Strategies

The students adopted several basic strategies to arrive at an editorially acceptable target language text. The author classified the students' processing problems into the following six categories, using Ivanova's (1999) criteria, and analyzed them by presenting the examples of the strategies that they had employed: 1) syntactic processing, 2) text integration, 3) text retrieval, 4) equivalence, 5) lexical access, and 6) TL delays.

With respect to English-to-English reformulation, the most frequent problems were associated with syntactic processing and text integration. Some students failed to recognize syntax, which induced an inability to construct a coherent representation for the SL chunk. For example, given the following sentence in the SL text, "Thank you for having this reception party for us," some of them reformulated it as "Thank you for inviting to the reception party to us." Others reformulated it as "Thank you for my reception party." Even though the sentence structure is simple, the syntactic processing seemed to be difficult for them to reproduce.

As another example, in the following sentence, "My hobby is playing baseball, and I am quite a good player, but not like Ichiro or Matsui, yet," many students did not accurately reformulate the underlined phrase in English. The most 
frequent errors in syntactic structure were "I am not good at Ichiro or Matsui, yet" and "I am not good player as much as Ichiro or Matsui." Otherwise, it was reformulated simply as "Ichiro and Matsui are better than me." On the other hand, when reformulating it into Japanese, they appeared to carry out the syntactic processing smoothly, achieving reformulation in proper Japanese. Thus, they may have processed this phrase instantaneously on the cognitive level.

With regard to text integration, problems frequently occurred when students rendered an SL English chunk into TL English. For example, in the sentence "Please help me any way you can," most students employed a strategy of deletion for the underlined phrase; that is, they omitted this chunk and said merely, "Please help me." They appeared not to be able to integrate this simple phrase into the TL English text appropriately on the spot. In contrast, when the TL was Japanese, most of them reformulated this sentence into plausible Japanese. They may have employed creative interpretation to compensate for an ineptitude with text integration by guessing the meaning of this chunk, based on previous knowledge.

With respect to equivalence, some students failed to produce an automatic equivalent because they had difficulty in selecting an appropriate one when there was a choice. In such cases, they appeared to employ a strategy of compromise - namely, to lower the acceptability standards for a TL production (Ivanova, 1999). For example, with the word "hospitality" or "reception," some of the students failed to use an appropriate Japanese equivalent, such as "omotenashi" or "gokoi," even though they identified these words as familiar to them. In such cases, they adopted a transliteration strategy in Katakana for these words and just said "hosupitariti."

For several proper nouns or unknown words in the SL text, they seemed to have difficulty retrieving all lexical items for reformulation. In this case, they would sometimes pause or even stop reformulating, which resulted in TL delays, during which some of them inferred the meaning of the words from the context or even invented a translation for them. When they recognized the TL delay, they sometimes seemed to have employed a strategy of overgeneralization or excessive paraphrasing by selecting a more abstract and less specific representation to compensate for the delay.

\section{Discussion}

\section{Testing of Research Question 1)}

For the present research, intensive reformulation treatment was administered for 1 hour out of a 3-hour weekly lesson, adding up to 15 hours during a semester. This length of time was initially assumed not to be sufficient for identifying marked development in reformulation skills; nevertheless, with regard to the SL to TL reformulation, the results indicated that the difference in the marks obtained between the mid-term and final examinations was statistically significant $(p<.05)$ for both English to Japanese and Japanese to English reformulation. Further, the findings showed that the students markedly developed also in reaction time on English to Japanese reformulation $(p<.001)$ as well as Japanese to English $(p<.001)$ between the two examinations. It seems that the students expedited their processing capacity during the administration period, demonstrating the efficacy of reformulation treatment for English to Japanese consecutive interpreting, as well as its Japanese to English counterpart.

In contrast, with respect to the language combination of SL to SL-namely, English to English and Japanese to Japanese - the development between the two examinations was not significant. Because English to English reformulation imposes a heavy burden on students to comprehend the logical structure and language components associated with syntax and style in the source text when listening, a major effort may be needed for verbal output of the equivalent products in English, which requires a fair amount of linguistic skill. The students who did not demonstrate reasonable linguistic skill when listening to English appeared not to be able to recreate the equivalent message orally in English either; this deficiency may be responsible for students' not being able to excel in English to English reformulation during such a short span of treatment. On the other hand, with regard to Japanese to Japanese reformulation, the students, unsurprisingly, displayed a high level of reformulating skills from the initial stage of treatment, which contributed to the lack of difference in the obtained marks between the midterm and final examinations.

In terms of the verbal performance, a phenomenal change occurred in the reaction time between the midterm and final examinations. In the midterm examination, the students seemed uncertain about what to say next when they had lexical and syntactic processing problems; however, in the final examination, they appeared to have become more aware of completing their delivery in a given span of time. Their hesitation in how to reproduce the message was significantly reduced, thereby resulting in a marked reduction in reaction time.

Testing of Research Question 2)

The present research hypothesizes that for the language pairs L2 to L2 and L2 to L1, if the SL comprehension is activated based on form (word for word), the accuracy of reformulation from L2 to L2 (English to English) would be likely to exceed the accuracy of reformulation from L2 to L1 (English to Japanese) as the higher degree of formal-lexical and syntactic similarity would be observed in the L2 to the L2 products than in their L2 to the L1 counterparts (Dam, 2002). Such would contribute to obtaining higher marks for L2 to L2 products than for their L2 to L1 counterparts. In reverse, if SL comprehension is based on meaning (sense), the accuracy of reformulation from L2 to L1 (English to Japanese) is likely to surpass the accuracy of reformulation from L2 to L2 (English to English) because the non-verbal representation of the meaning of the SL would exert a more positive influence over the TL production in L1 Japanese than the one in L2. 
According to the ITT, sense (meaning) arising from non-verbal representation is not contained in any language or text but arises from cues given in oral discourse plus cognitive complements from the target listener. More specifically, it states that we all experience deverbalization in everyday communication (Pöchhacker, 2016), which implies that sense is likely to be more easily modulated into the target production when reformulated in L1 as the working language rather than in L2. Hence, if comprehension stems from meaning, subsequent reformulation in L1 may be further expedited, which leads to more marks obtained through the L2 to L1 reformulation than from its L2 to L2 counterpart.

Another possibility is that there is no pronounced difference in marks obtained between the L1 to L2, and the L2 to L1 reformulation. This assumption has major implications that parallel processing of the TL would be activated during the SL comprehension, which would not have precedence over TL processing during the input phase but would rather be exercised in parallel with TL production.

Interestingly, when comparing every possible language combination, the findings indicated that only one pair out of six showed no statistical differences from each other in obtained marks. This combination is the English to English reformulation and its English to Japanese counterpart. Further, a close examination of the two products revealed that the correlation in the products of English to English reformulation and its English to Japanese counterpart was significantly high: $r=.80$ for the midterm examination and $r=.88$ for the final examination. The qualitative analysis showed that, in most cases, the specific comprehension problems in logical structure and language components that occurred in the English to English reformulation were also observed in the very same phrase or sentences in the English to Japanese consecutive interpreting; furthermore, the errors occurring in the English to English reformulation were almost identical with the ones in the English to Japanese counterpart.

Turning to reaction time, only the same pair (English to English and English to Japanese) showed no significant difference from each other in the midterm and final examinations. As reaction time, which indicates cross-linguistic effects or load effects (Dong \& Lin, 2013), is positively associated with inertia in SL comprehension and TL processing, reaction time would have varied between two directions of reformulations if they had been activated by different dimensions - that is, either form or meaning. Nonetheless, neither the obtained marks nor the reaction time produced a statistical difference in this pair, which suggests that so far as English to English, and English to Japanese reformulations are concerned, SL comprehension may be activated, not by either the form-based or meaning-based conceptual representation taking precedence over the reformulating phase, but by parallel processing, in which the TL processing is likely to be integrated into SL comprehension.

Earlier studies have presented evidence that the lexical link from L2 to L1 is stronger than the one from L1 to L2; thus, it is easier for L2 words to activate their L1 counterparts than vice versa (Kroll \& Stewart, 1994). This hallmark feature - the stronger lexical link from L2 to L1 - is likely to have rendered possible a smooth English-to-Japanese reformulation, which may serve to co-activate SL and TL processing. This study, however, provides no further answer as to which factor renders parallel processing possible. In summary, all it suggests is that in the comprehension and reformulation phases, as long as the SL is L2, the TL parallel processing may occur during SL comprehension regardless of whether the TL is $\mathrm{L} 1$ or $\mathrm{L} 2$.

In reverse, when the SL is L1 - namely, in the reformulation of Japanese to Japanese and Japanese to English-the statistical difference between the two pairs, in terms of both marks obtained and reaction time, was pronounced. As earlier studies noted, the lexical-conceptual link is stronger for L1 words than for L2 words, which results in easier mapping between form and meaning for L1 words than for L2 words (Dong, Gui, \& MacWhinney, 2005, Dong \& Lin, 2013; Kroll \& Stewart, 1994); thus, it would seem clear that the Japanese to Japanese language link is much stronger than that for its Japanese to English counterpart. Furthermore, a close examination of the products reformulated from Japanese to Japanese reveals that lexical similarity, in which the lexical and syntactic structures in the Japanese source texts exactly matched those in the Japanese target text, is a more salient feature than lexical dissimilarity. Paraphrasing was rarely performed in the Japanese TL, but exact literal repetition of each lexical item and syntactic structure was displayed in the TL products. As lexical similarity and lexical dissimilarity can be considered as general yardsticks determining form-based or meaning-based interpreting (Dam, 1998), it is most likely that comprehension from Japanese to Japanese reformulation is based on form. Nevertheless, this observation does not in any way exclude meaning from the reformulating process. As this language pair hits the highest score by far, showing almost full marks (out of 30 points, 28.93 for the midterm and 29.52 for the final), and considering it also shows the shortest reaction time, the conceptual representation of this language combination may constitute the meaning, too. A stronger lexical-conceptual link for an L1 word than for an L2 word may suggest that the phase activated by form is probably easily modulated to the meaning phase, too. This hypothesis seems to be in line with the statement that form-based and meaning-based reformulation, rather than being mutually exclusive, may complement each other (Dam, 1998).

Next, when comparing the bidirectional language pairs - that is, English to Japanese and Japanese to English pairs - a statistical difference was observed in the marks obtained as well as in the reaction time on both examinations. More specifically, the Japanese to English combination produced higher scores than the English to Japanese counterpart; in fact, the Japanese to English pair hit the highest score of all, excluding Japanese to Japanese reformulation. Such a difference in marks obtained implies that comprehension may be activated by different conceptual representations between two combinations, either form-based or meaning-based. As aforementioned, given that the comprehension of an English to Japanese pair may be activated in parallel with TL processing, it is assumed 
that comprehension in the Japanese-to-English language combination is probably based on meaning or on form. Given that form-based comprehension was exercised in the Japanese-to-English reformulation, word-for-word translation would have been extremely difficult because the morphosyntactic structure is significantly different between the two languages, as Japanese is a verb-last language and English is the reverse. If form-based comprehension had been exercised, it would have resulted in an awkward rendition, which suggests that form-based comprehension is unlikely to have occurred, given that the students obtained such high scores. In fact, in the interpreting community, there appears to be agreement that in order to optimize quality, interpreting should be performed based on meaning, not on form (word for word), because going through meaning instead of seeking direct linguistic correspondence allows for better comprehension of the speaker's intentions and better reformulation in the TL, with less linguistic interference and more idiomatic expression (Gile, 2009). In this context, high scores in reformulation from Japanese to English imply that comprehension is most likely to be activated by meaning.

In summary, the present study suggests that on the one hand, with regard to the language pair of L2 to L2 or L2 to L1, parallel processing occurs; on the other hand, in an L1 to L1 pair, form-based comprehension is likely to be exercised, which may be easily modulated into the meaning phase. With respect to an L1 to L2 pair, meaning-based comprehension may be activated. In this context, the findings of L2 to L1 research exactly matched the earlier view that only in L2-L1 interpreting does TL parallel processing occur when investigating bidirectional L1 to L2 and L2 to L1 interpreting (Dong \& Lin, 2013). Concerning L1 to L2 reformulation, the findings of the present study match the serial view- that is, interpreted texts are produced mainly on the basis of non-verbal representation of source text meaning (Seleskovitch, 1978).

\section{CONCLUSION}

The aim of this study was twofold. The first was to investigate the efficacy of reformulation practice for consecutive interpreting training. There was clearly a significant difference in marks obtained between the midterm and final examinations with regard to bidirectional SL and TL reformulation. More specifically, the students markedly developed their consecutive interpreting skills from L2 to L1 as well as from L1 to L2 during the administration period. However, other variables showed mixed effects. With respect to reformulation of the L2 to L2 pair, the efficacy of treatment was not pronounced. This result may arise from a deficiency in the students' processing capacity for L2 to L2 reformulation, which required the students to be highly proficient in the L2. This implies that it seems to be extremely difficult to enhance English proficiencies, which is critical in L2 to L2 reformulation, during such a short time of treatment.

Next, the present study explored the process of consecutive interpreting by invoking three distinct theoretical models. It concluded that as long as the source language is the L2, it is most likely that TL processing may occur parallel to SL comprehension. In contrast, in L1 to L2 reformulation, meaning-based comprehension would be activated, while in the L1 to L1 reformulation, form-based comprehension may be exercised, which is likely to be easily modulated into meaning. Nonetheless, these observations do not in any way exclude meaning or form or parallel processing from the respective pairs; rather, the form-based and meaning-based representations appear to be intricately intertwined and to co-occur in one language combination, from which we may conclude that the nature of the conceptual representation of the interpreting process is still uncertain. Nevertheless, the present research on multidirectional reformulation through direct contact between SL and TL linguistic products and including reaction time may provide some perspective on interpreting processing accounts, which may shed light on the salient link in the language combination.

\section{LIMITATIONS}

It should be noted here that these findings concerning the reformulating process claim validity only for the data in the present research, which have limitations and weaknesses. For instance, the present study involved relatively few participants, only 27 students. Furthermore, they were all registered in introductory interpreting courses, which means that none of them had undergone interpreting training in the past. Data drawn from participants in different developmental stages of interpreting experience might produce different results from those found in the present research. This implies that it is difficult to draw a generalization concerning the interpreting process from the presented materials. Future studies may need to increase sample size and multiply replication, so as to offset, in part, the difficulties of empirical study. Nevertheless, these findings may serve to demonstrate the potential usefulness of comparative analysis between the source and the target texts when exploring the interpreting process.

\section{REFERENCES}

[1] Alvstad, C., Hild, A., \& Tiselius, E. (Eds.) (2011). Methods and strategies of process research: Integrative approaches in translation studies. Amsterdam, Holland: John Benjamins.

[2] Cokely, D. (1992a). Interpretation: A sociolinguistic model, Burtonsville, MD: Linstok Press.

[3] Dam, H. (2002). Lexical similarity vs lexical dissimilarity in consecutive interpreting: A product-oriented study of form-based vs meaning-based interpreting. In F. Pochhacker \& M. Schlesinger (Eds.), The interpreting studies reader (pp. 266-277). London, UK: Routledge.

[4] Dong, Y., \& Lin, J. (2013). Parallel processing of the target language during source language comprehension in interpreting. 
Bilingualism: Language and Cognition, 16(3), 682-692.

[5] Dong, Y., Gui, S., \& MacWhinney, B. (2005). Shared and separate meanings in the bilingual mental lexicon. Bilingualism: Language and Cognition, 8, 221-238,

[6] Gile, D. (2009). Basic concepts and models for interpreter and translator training (rev. ed.). Amsterdam, Holland: John Benjamins.

[7] Gran, L. (1989). Interdisciplinary research on cerebral asymmetries: Significance and prospects for the teaching of interpretation. In L. Gran \& J. Dodds (Eds.), The theoretical and practical aspects of teaching conference interpretation (pp. 93-100). Udine, Italy: Campanotto Editore.

[8] Jin, Y. (2010). Is working memory working in consecutive interpreting? (Unpublished doctoral dissertation). University of Edinburgh, Scotland. Retrieved October 24, 2017 from https://core.ac.uk/download/pdf/280080.pdf.

[9] Ivanova, A. (1999). Discourse processing during simultaneous interpreting: An expertise approach (Unpublished doctoral dissertation). Cambridge University, UK.

[10] Kroll, J. F., \& Stewart, E. (1994). Category interference in translation and picture naming: Evidence for asymmetric connections between bilingual memory representations. Journal of Memory and Language, 33, 149-174.

[11] Macizo, P., \& Bajo, M. T. (2004). When translation makes the difference: Sentence processing in reading and translation. Psicológica, 25, 181-205.

[12] Macizo, P., \& Bajo, M. T. (2006). Reading for repetition and reading for translation: Do they involve the same process? Cognition, 99, 1-34.

[13] Mukai, G., Maruyama, Y., \& Matsuoka, H. (2004). Tsuuyakushiki gakushuhou de dondon hanaseru dondoneikaiwa. Tokyo, Japan: Kennkyusha.

[14] Pöchhacker, F. (2016). Introducing interpreting studies ( $2^{\text {nd }}$ ed.). London, UK: Routledge.

[15] Seleskovitch, D. (1978a). Interpreting for international conferences. Washington, DC: Pen and Booth.

[16] Seleskovitch, D. (1978b). Language and cognition. In D. Gerver \& H. W. Sinaiko (Eds.), Language interpretation and communication (pp. 333-341). Boston, MA: Springer.

[17] Setton, R. (1998/2002). "Meaning assembly in simultaneous interpretation.” In F. Pöchhacker \& M. Schlesinger (Eds.), The interpreting studies reader (pp. 178-202). London, UK: Routledge.

[18] Setton, R. (1999). Simultaneous interpretation: A cognitive-pragmatic analysis. Amsterdam, Holland: John Benjamins.

[19] Tiselius, E. \& Jenset, G. (2011). Process and product in simultaneous interpreting: What they tell us about experience and expertise. In C. Alvstad, A. Hild, \& E. Tiselius (Eds.), Methods and strategies of process research (pp. 269-300). Amsterdam, Holland: John Benjamins.

[20] Viaggio, S. (1992). The praise of sight translation (and squeezing the last drop thereout of). The Interpreters' Newsletter, 4, 45-58.

[21] Yamada, H. (2015). Introduction of written test in evaluation of English-Japanese interpreting classes at universities in Japan. Interpreting and Translation Studies, 15, 91-112.

Hiroko Yamada is an associate professor at the University of Foreign Language, Kansaigaidai College, Japan. She obtained her master's degree at Ritsumeikan University, and is registered in a doctoral course at the Graduate School of Kyoto University. She is interested in interpreting pedagogy, and has a great deal of experiences in consecutive and simultaneous interpreting. 